\title{
LIBERDADE: A CONDIÇÃO DE POSSIBILIDADE DO PLURALISMO A PARTIR DO PENSAMENTO DE RAWLS
}

\author{
LIBERTY: THE POSSIBILITY CONDITION OF PLURALISM FROM RAWS' \\ THOUGHT
}

\section{LIBERTAD: LA CONDICIÓN DE POSIBILIDAD DEL PLURALISMO A PARTIR DEL PENSAMIENTO DE RAWLS}

\author{
BRUNO CAMILLOTO \\ http://orcid.org/0000-0003-4067-4272 / http://lattes.cnpq.br/8069472213279914 brunocamilloto@gmail.com \\ Universidade Federal de Ouro Preto, UFOP. \\ Ouro Preto, MG, Brasil.
}

\begin{abstract}
RESUMO
Como estabelecer normas de convivência entre um indivíduo que crê em algum dogma de fé (religiosidade) e outro que não possui crença religiosa? O presente ensaio propõe que o conceito de liberdade seja o fundamento radical de uma sociedade plural. A partir de John Locke e John Stuart Mill se reconstrói o conceito de liberdade, expondo os principais argumentos do liberalismo clássico. Com John Rawls, a liberdade torna-se o primeiro princípio de justiça de uma sociedade bem-ordenada, fazendo parte da razão pública e de uma concepção política de justiça. Assim, defende-se a liberdade como condição necessária do pluralismo, ou seja, como fundamento radical de uma sociedade plural.
\end{abstract}

Palavras-chave: Liberalismo; pluralismo; tolerância.

\begin{abstract}
How to establish rules for coexistence between a person who has a religious faith and another one who does not have any faith? This essay proposes that the concept of liberty is the basis of a plural society. According to John Locke e John Stuart Mill, this paper reconstructs the concept of liberty and exposes the main arguments of classical liberalism. In accordance with John Rawls, liberty becomes the first principle of justice as fairness of a well-ordered society, which is part of the public reason and the political conception of justice. It defends liberty as the necessary condition of pluralism, that is, liberty is a radical basis of a plural society.
\end{abstract}

Keywords: Liberalism; pluralism; tolerance.

\section{RESUMEN}

¿Cómo establecer normas de convivencia entre un individuo que cree en algún dogma de fe (religiosidad) y otro que no posee creencia religiosa? El presente ensayo propone que el concepto de libertad sea el fundamento radical de una sociedad plural. A partir de John Locke y John Stuart Mill se reconstruye el concepto de libertad exponiendo los principales argumentos del liberalismo clásico. Con John Rawls, la libertad se convierte en el primer principio de justicia de una sociedad bien ordenada, formando parte de la razón pública y de una concepción política de justicia. Se defiende la libertad como la condición necesaria del pluralismo, o sea, como fundamento radical de una sociedad plural.

Palabras clave: Liberalismo; pluralismo; tolerancia. 


\section{SUMÁRIO}

INTRODUÇÃO; 1 CONTORNOS LIBERAIS: UMA COMPREENSÃO DO LIBERALISMO POLÍTICO; 2 LIBERALISMO CLÁSSICO: OS FUNDAMENTOS DA LIBERDADE INDIVIDUAL; 3 RAWLS, A LIBERDADE E O PLURALISMO; CONCLUSÃO; REFERÊNCIAS.

\section{INTRODUÇÃO}

Este ensaio propõe uma defesa radical da liberdade como valor político fundante de sociedades democráticas e plurais. Constatado o fato do pluralismo, ${ }^{1}$ questiona-se como uma sociedade, profundamente diversa, cujos indivíduos possuem concepções distintas e contrárias de vida, é capaz de se manter coesa e, ao mesmo tempo, de tolerar as diversidades em seu interior? Propõe-se que a ideia de liberdade seja compreendida numa radicalidade conceitual capaz de se tornar condição necessária para estruturar uma sociedade plural, na qual deva estar contemplada a diversidade dos indivíduos.

O objetivo é investigar e reconstruir o conteúdo conceitual da liberdade dentro da tradição do liberalismo, verificando se esse conceito é capaz de fornecer fundamento político às sociedades plurais contemporâneas. Para tanto, parte-se da reconstrução dos elementos do liberalismo clássico, nos termos apresentados por John Locke e John Stuart Mill, verificando-se o conteúdo referente ao conceito de liberdade e sua relação com a contemporaneidade. Ainda, como objetivo específico, verifica-se a relação entre o conteúdo clássico da liberdade frente a sua atualização feita por John Rawls a partir da publicação de 'Uma Teoria da Justiça'.

A presente investigação justifica-se diante das tensões existentes entre as liberdades civis básicas dos indivíduos em sociedades plurais na contemporaneidade. Essas tensões podem ser percebidas pela atuação do Estado frente à autonomia dos cidadãos de decidirem seus próprios projetos de vida e pela interferência de outros indivíduos sobre a esfera de liberdade dos seus concidadãos. Como hipótese de trabalho, tem-se que a ideia de liberdade, pensada e construída em sua radicalidade conceitual, é capaz de fornecer um conteúdo teórico e prático para fundamentar uma sociedade plural, o que argumentativamente se testa a partir dos contextos apresentados pela perspectiva liberal clássica (Locke e Mill) e liberal contemporânea (Rawls) com a formulação de uma questão prática sobre a liberdade religiosa. A questão que se

\footnotetext{
${ }^{1}$ RAWLS, John. Liberalismo Político. Tradução de Álvaro de Vita. São Paulo: Editora WMF Martins Fontes, 2011, p. 42. Para Rawls, o pluralismo razoável diz respeito à possibilidade de decidir-se por uma ou outra razão após a formação do consenso constitucional. Para tanto, devem considerar-se as razões conflitantes como razoáveis, gerando, por fim, uma tolerância no procedimento discursivo deliberativo.
} 
apresenta é: como estabelecer normas de convivência entre um indivíduo que crê em algum dogma de fé (religiosidade) e outro que não possui crença religiosa? A escolha da liberdade religiosa justifica-se pelo fato de que, em sociedades contemporâneas, a liberdade de crença constitui um dos pilares de uma sociedade diversificada e plural. Sendo assim, a liberdade como fundamento radical do pluralismo é argumento testado para se buscar um fundamento teórico e prático capaz de conciliar perspectivas antagônicas, como uma pessoa religiosa e outra não religiosa.

O ensaio situa-se no âmbito de uma pesquisa de vertente jurídico teórica, de caráter analítico e normativo, cujos procedimentos investigativos fundam-se na análise de blocos de conteúdo, a partir dos quais se construirá esquemas conceituais específicos utilizando, ainda, de processos discursivos e argumentativos para o convencimento sobre a validade dos esquemas propostos. Argumenta-se, por fim, que somente o direito de liberdade, compreendido como a possibilidade do desenvolvimento livre da personalidade humana, pode ser o responsável por estruturar uma sociedade plural, abrigando a diversidade dos indivíduos dentro do ambiente social.

\section{CONTORNOS LIBERAIS: UMA COMPREENSÃO DO LIBERALISMO POLÍTICO}

As sociedades contemporâneas não podem prescindir da liberdade individual. Qualquer que seja a forma de pensar, estabelecer e desenvolver a convivência social sempre será necessário levar em consideração o indivíduo como sendo um núcleo conceitual articulador da tensão entre a liberdade individual e o poder político estatal. Não se desconsidera que os seres humanos são seres sociais, isto é, são fabricados na convivência social e resultantes das diversas relações de intersubjetividades que desenvolvem. Contudo, o conceito de indivíduo, historicamente situado permitiu que as sociedades contemporâneas construíssem sistemas normativos jurídicos capazes de organizar o comportamento dos cidadãos permitindo, ainda, alguma estabilidade social. Essa perspectiva apresenta as inúmeras possibilidades de compreensão do conceito de liberdade que fazem parte do contexto do liberalismo. No contexto da tradição liberal, o conceito de Direito será articulado com os de indivíduo, liberdade, autonomia, pluralismo, tudo como forma de verificar as possibilidades de fundamentar uma sociedade plural.

Todas as classificações realizadas pelas teorias sofrem um problema de reducionismo. Positivismo, jusnaturalismo, liberalismo, igualitarismo e seus congêneres são conceitos amplos 
que devem ser utilizados em contextos específicos para que façam sentido na construção de um discurso racional. Sob o conteúdo desses conceitos, muitas ideias são colocadas lado a lado sem que estejam, necessariamente, em conexão umas com as outras. Se, por um lado, as classificações conceituais apresentam esse problema, por outro, o pensamento humano não consegue se estabelecer sem formar um contexto conceitual geral capaz de fazer conexões e aplicações dos conteúdos dos conceitos utilizados em determinadas situações de aplicações daqueles conteúdos. Ao lado da insuficiência das classificações e diante da realidade que se apresenta muito mais rica e complexa, tem-se a necessidade do pensamento humano fazer recortes contextuais e conceituais aglomerando e separando os conteúdos dos conceitos por semelhanças e diferenças de forma que o indivíduo possa utilizar os conceitos nas práticas sociais quotidianas.

O liberalismo, portanto, pode ser compreendido, ao longo da história, como um conceito que abarca inúmeras possibilidades de compreensão, a partir das perspectivas econômica, política, moral e religiosa. A primeira questão que se coloca é a construção de um conteúdo conceitual que represente a ideia central do que se entende por liberalismo. Ainda que ciente das dificuldades envolvidas, não é possível se eximir dessa tarefa sob pena de restar infrutífero o esforço de pensar sobre o conceito de liberdade no interior de sociedades plurais contemporâneas.

Nesse contexto, propõe-se uma análise do liberalismo político que deverá ser compreendido, nos limites do presente ensaio, como uma construção discursiva capaz de estabelecer e fundamentar, teórica e praticamente, a liberdade individual como fundamento de sociedades plurais contemporâneas. Propõe-se, assim, que o núcleo do conceito de liberalismo seja discursivamente construído em torno da ideia de autonomia moral do indivíduo.

Por autonomia moral individual entende-se a capacidade dos seres humanos, compreendidos como agentes racionais, de elaborarem seus próprios planos de ação a partir da racionalidade que thes é inerente ou, em outros termos, a capacidade de se autogovernar. Esse núcleo do conceito de liberalismo apresenta a liberdade individual como valor fundamental.

Dos clássicos, os pensamentos dos autores John Locke e John Stuart Mill apresentam construções conceituais da ideia de liberdade bastante interessantes para os propósitos deste ensaio, o que, desde já, permite compreender o conceito de liberdade relacionado com o conceito de indivíduo como detentor de direitos individuais. A ideia do direito à liberdade leva à reflexão sobre (a) o papel do Estado, (b) os limites da tolerância e (c) o fundamento dos direitos individuais. 
Em Locke a liberdade é construída a partir da necessidade de dar legitimidade ao poder político no sentido de que:

$\mathrm{Na}$ sociedade, a liberdade do homem não deve estar de forma alguma sujeita ao poder legislativo, salvo o estabelecido por consentimento da comunidade civil, nem pelo domínio de qualquer vontade, ou impedimento de qualquer lei, exceto o que for aprovado pelo legislativo, de acordo com a confiança que se deposita nele. $^{2}$

Elemento central da proposta de Locke, o consentimento é reforçado no pensamento de Mill $^{3}$ que atribui ao indivíduo a soberania sobre si mesmo em todos os sentidos (especialmente sobre seu corpo e pensamento). ${ }^{4}$ Esse argumento explicita a capacidade humana de tomada de decisão a partir da concepção do indivíduo como um agente racional. 0 argumento também coloca em questão o poder de um indivíduo sobre outro: se, por um lado o núcleo central do liberalismo é o conceito de indivíduo, por outro há que se pensar na relação desse indivíduo com os demais no contexto de relações intersubjetivas.

Os conceitos de consentimento de Locke $^{5}$ e de autogoverno de Mill, ${ }^{6}$ centrais no liberalismo clássico, são fundamentais para a compreensão das sociedades plurais contemporâneas. Parte-se do conceito de indivíduo como centro de imputação conceitual do conteúdo normativo da ideia de liberdade. O liberalismo, portanto, toma para si a defesa e realização da liberdade no campo político nas sociedades contemporâneas, requisitando proteção dos direitos individuais como forma de autorrealização dos indivíduos.

A partir da publicação de 'Uma Teoria da Justiça', em 1971, Rawls recoloca o tema da Justiça na esfera pública reestabelecendo o debate sobre o liberalismo e a justiça. ${ }^{7}$ Com Rawls, busca-se compreender as possibilidades e os limites da tolerância liberal para a fundamentação de uma sociedade plural. A partir do conceito clássico de liberalismo, consignado nos pensamentos de Locke e Mill, defender-se-á que o conteúdo do primeiro princípio de justiça de

\footnotetext{
${ }^{2}$ LOCKE, John. Segundo tratado sobre o governo civil. Tradução Marsely de Marco Dantas; Apresentação de notas Daniel Moreira Miranda. São Paulo: EDIPRO, 2014, p. 41.

${ }^{3}$ MILL, Stuart. Sobre a liberdade. Tradução e organização: Ari R. Tank. São Paulo: Hedra, 2010, p. 50.

${ }^{4} \mathrm{O}$ argumento de Mill é forte justamente porque usa um conceito político (soberania) para conceber a liberdade individual.

${ }^{5}$ LOCKE, John. Segundo tratado sobre o governo civil. Tradução Marsely de Marco Dantas; Apresentação de notas Daniel Moreira Miranda. São Paulo: EDIPRO, 2014.

${ }^{6}$ MILL, Stuart. Sobre a liberdade. Tradução e organização: Ari R. Tank. São Paulo: Hedra, 2010.

${ }^{7}$ RAWLS, John. Uma teoria da justiça. Tradução Jussara Simões; revisão técnica Álvaro de Vita. $3^{a}$ ed. São Paulo: Martins Fontes, 2008.
} 
Rawls possui força argumentativa suficiente para fundamentar uma sociedade plural. 0 primeiro princípio de justiça de Rawls é apresentado nos seguintes termos:

Cada pessoa tem um direito igual a um sistema plenamente adequado de direitos e liberdades iguais, sistema esse que deve ser compatível com um sistema similar par todos. E, neste sistema, as liberdade políticas, e somente estas, devem ter seu valor equitativo garantido. ${ }^{8}$

A partir do primeiro princípio de justiça conclui-se que o conceito de liberdade é capaz de justificar, pública e racionalmente, os arranjos normativos de uma sociedade que busca preservar a diversidade social se constituindo politicamente como uma sociedade plural.

\section{LIBERALISMO CLÁSSICO: OS FUNDAMENTOS DA LIBERDADE INDIVIDUAL}

O núcleo do liberalismo é concebido em torno da ideia de autonomia compreendida aqui em dois sentidos: (a) autonomia moral como a capacidade dos indivíduos de elaborarem seus próprios planos de ação a partir da racionalidade que lhes é inerente ou, em outros termos, a capacidade de autogovernar-se, e (b) autonomia política como independência legal e garantia de participação compartilhada dos cidadãos na esfera pública no exercício do poder político. ${ }^{9}$

Recuperando a ideia hobbesiana de liberdade como ausência de interferência, Locke (1632-1704) faz dois movimentos argumentativos que podem ser considerados como a inauguração da tradição liberal moderna: (a) Locke desafia a autoridade da Coroa em sociedades de Constituição mista argumentando que a fonte da autoridade política não está no Poder Divino. Essa tese nega aquela apresentada por Robert Filmer no livro Patriarca segundo a qual Deus sujeitou a humanidade ao monarca. Nesse giro argumentativo, Locke recua ao conceito de Estado de Natureza e concebe os indivíduos como seres detentores do direito de liberdade naquele Estado e que devem ser preservados no Estado Civil e (b) negando a autoridade normativa do Poder Divino, Locke propõe que a fonte da autoridade política está na liberdade natural. Segundo esse argumento, os homens são livres por natureza e, ao viver em sociedade civil, são capazes de instituírem os termos dessa convivência de forma a preservar a liberdade já existente no Estado de Natureza.

\footnotetext{
8 In: RAWLS, John. Liberalismo Político. Tradução de Álvaro de Vita. São Paulo: Editora WMF Martins Fontes, 2011, p. 06.

${ }^{9}$ RAWLS, John. Liberalismo Político. Tradução de Álvaro de Vita. São Paulo: Editora WMF Martins Fontes, 2011, p. XLVIII.
} 
Assim, o Segundo tratado do governo civil de Locke $^{10}$ é uma árdua defesa da Supremacia Parlamentar, do Estado de Direito e do Governo Constitucional. Para os contornos deste ensaio, trabalha-se o argumento da liberdade como fundamento de legitimidade das normas de uma determinada sociedade. Na busca pelos fundamentos de legitimidade do poder político, Locke propõe que "a liberdade natural do homem deve ser livre de qualquer poder superior na Terra, sem estar sujeito à vontade ou autoridade legislativa dos demais homens, mas deve ter, tão somente, a lei natural como seu preceito". ${ }^{11}$

Com Locke, a dimensão política do conceito liberdade aflora e traz novas possibilidades de reflexão sobre o conteúdo daquele conceito. Buscando afastar os fundamentos do Estado Absoluto, compreendido como aquele no qual o poder é exercido sem limites e cujo fundamento é a vontade divina, Locke propõe que o Estado seja fundado nos direitos individuais que não podem ser violados pelas instituições da sociedade política. Assim, o liberalismo em Locke já articula as duas dimensões da autonomia apresentadas anteriormente: moral e política. A autonomia moral se funda na Lei Natural pré-existente ao Estado Civil. A autonomia política surge com a necessidade de constituir as bases da coexistência entre os indivíduos dentro da sociedade ao mesmo tempo em que se deve preservar a liberdade individual. Em 'Carta acerca da Tolerância’, Locke afirma que “(...) a comunidade é uma sociedade de homens constituída apenas para a preservação e melhoria dos bens civis de seus membros”. ${ }^{12}$

A dimensão política do liberalismo de John Locke traz à reflexão a ideia do consentimento dos indivíduos, que reflete tanto no poder do governante quanto no próprio conceito lockeano de liberdade. Ao tratar “Do início das sociedades políticas”, Locke explicita a importância do consentimento afirmando que "os homens são, como já foi dito aqui, todos livres, iguais e independentes por natureza; nenhum pode ser demovido dessa condição, e sujeito ao poder político de outro, sem o seu consentimento". ${ }^{13}$

O consentimento em relação ao exercício do poder torna-se o fundamento da associação política a partir do pensamento de John Locke. Assim, o poder público só encontra fundamento diante (a) do consentimento dos indivíduos capaz de estabelecer as perspectivas de sua liberdade dentro da sociedade política e (b) se o governo estabelecido pelo consentimento

\footnotetext{
${ }^{10}$ LOCKE, John. Segundo tratado sobre o governo civil. Tradução Marsely de Marco Dantas; Apresentação de notas Daniel Moreira Miranda. São Paulo: EDIPRO, 2014.

${ }^{11}$ LOCKE, John. Segundo tratado sobre o governo civil. Tradução Marsely de Marco Dantas; Apresentação de notas Daniel Moreira Miranda. São Paulo: EDIPRO, 2014, p. 41.

12 LOCKE, John. A letter concerning toleration. Translated by Willian Popple, 1689. Disponível em: http://www.dominiopublico.gov.br/download/texto/mc000173.pdf. Acesso em: 26 jan. 2017, p. 06.

${ }_{13}$ LOCKE, John. Segundo tratado sobre o governo civil. Tradução Marsely de Marco Dantas; Apresentação de notas Daniel Moreira Miranda. São Paulo: EDIPRO, 2014, p. 85.
} 
estiver limitado às leis produzidas pelos indivíduos. Nessa perspectiva, os contornos do pensamento político moderno se forjam na dramática relação entre o indivíduo - cujo conceito liberal reivindica a prioridade das liberdades (direitos) individuais - e o Estado - cujo conceito liberal exige uma abstenção em relação às liberdades individuais como forma de oposição ao poder absoluto oriundo do regime absolutista até então vigente. Em síntese, o liberalismo lockeano apresenta como valor fundamental a liberdade individual ${ }^{14}$.

A formulação do conceito de liberdade ganha outra importante contribuição na obra de John Stuart Mill (1806-1873). A limitação do poder público, fundamental para o pensamento de Locke, já não é o objeto das preocupações de John Stuart Mill cuja proposta já pressupõe um sistema constitucional capaz de organizar, política e juridicamente, a sociedade. Sobre a liberdade de Mill, ${ }^{15}$ portanto, não é uma obra em defesa da sociedade contra a tirania dos governantes, mas, sim, apresenta uma defesa do conceito de liberdade e uma preocupação com os abusos que podem ser cometidos pelas maiorias formadas no interior da sociedade. ${ }^{16}$ Ao fazer esse movimento argumentativo, Mill fornece substrato teórico e prático para se pensar nas possibilidades de manutenção da diversidade interna à sociedade. A partir dessa perspectiva, tem-se a possibilidade de pensar numa organização social plural que seja capaz de preservar os diferentes indivíduos em seu interior. O conceito de liberdade a ser tratada por Mill é a liberdade civil ou social, compreendida como aquela liberdade a ser estabelecida na convivência (coexistência) dentro da sociedade.

Em razão da importância da formulação argumentativa de Mill, ${ }^{17}$ apresentam-se os elementos discursivos do princípio liberal de Mill de forma destacada, já que "único objetivo pelo qual a humanidade pode, de forma individual ou coletiva, interferir com a liberdade de ação de qualquer de seus membros, é a proteção dela própria”. Do enunciado constata-se que a autorização dada à humanidade para a interferência na esfera de ação de qualquer indivíduo somente se justifica pela sua proteção. Em seguida, Mill irá conectar esse argumento àquilo que ficou conhecido como o princípio do dano, ou seja, ele reelabora o argumento referindo que "o

\footnotetext{
${ }^{14}$ DANNER, Leno Francisco. A reformulação do liberalismo clássico por John Rawls. Fundamento Revista de Pesquisa em Filosofia. Universidade Federal de Ouro Preto. v. 1 n. 3, maio - ago. 2011. Ouro Preto: Ed UFOP, 2011. p. 121-152.

${ }^{15}$ MILL, Stuart. Sobre a liberdade. Tradução e organização: Ari R. Tank. São Paulo: Hedra, 2010.

${ }^{16}$ DALAQUA, Gustavo Hessman. A defesa miliana da liberdade de expressão. Fundamento Revista de Pesquisa em Filosofia. Universidade Federal de Ouro Preto. v. 1, n. 3, maio-ago. 2011. Disponível em: http://www.revistafundamento.ufop.br/index.php/fundamento/article/view/40/31. Acesso em: 15 jan. 2017.

${ }^{17}$ MILL, Stuart. Sobre a liberdade. Tradução e organização: Ari R. Tank. São Paulo: Hedra, 2010, p. 49.
} 
único propósito pelo qual o poder pode ser constantemente exercido sobre qualquer membro de uma comunidade, contra a vontade deste, é o de prevenir danos para os outros membros". ${ }^{18}$

Articulando os dois argumentos, tem-se que, ao indivíduo, deve ser assegurado o maior espaço de ação possível dentro da estrutura social. Neste caso, o espaço de liberdade dos indivíduos deve ser o mais amplo possível. Somente nos casos em que a ação individual for causa de dano a outro indivíduo é que a comunidade está autorizada a interferir sobre a vontade daquele primeiro. Por fim, Mill apresenta seu mais forte argumento em defesa da liberdade individual: "Sobre si mesmo, sobre seus próprios corpo e mente, o indivíduo é soberano". ${ }^{19}$

A pequena frase de Mill é capaz de explicitar a força da argumentação em torno de um dos conceitos centrais do liberalismo: a autonomia moral do indivíduo. Esse argumento explicita a capacidade humana de tomada de decisão a partir da concepção do indivíduo como um agente racional. $\mathrm{O}$ argumento também coloca em questão o poder de um indivíduo sobre outro, isto é, se por um lado o núcleo central do liberalismo é o conceito de indivíduo, por outro há que se pensar na relação desse indivíduo com os demais. Estabelece-se, assim, uma perspectiva intersubjetiva que revela como ponto de reflexão as possibilidades do uso do poder no âmbito da sociedade. Nesse sentido, Mill reforça seu argumento quando diz que "se toda a humanidade, exceto uma pessoa, tivesse uma opinião, e essa pessoa tivesse uma opinião contrária, a humanidade não teria mais justificativas para silenciá-la do que ela para silenciar a humanidade". ${ }^{20}$

A garantia das liberdades individuais de pensamento e de expressão no âmbito da sociedade se conecta com o conceito de autonomia em dois sentidos: (a) atribui ao indivíduo o direito de exercer sua liberdade da forma mais ampla possível como forma de realização do seu projeto de vida (autonomia moral) e (b) exige que o poder público e os demais concidadãos se abstenham de produzir interferência no exercício daquela liberdade (autonomia política). $\mathrm{Na}$ proposta conceitual de Mill, a liberdade pode ser compreendida como fundamento de sociedades plurais que têm por objetivo, dentre outros, preservar as diferenças individuais no ambiente social proporcionando a coexistência da/na diversidade.

Os pensamentos de Locke e Mill, apesar de distintos nos objetivos e nas razões apresentadas em defesa da liberdade, complementam-se no tocante às possibilidades de compreensão de um conceito de liberdade que seja capaz de preservar a unidade individual irredutível que é o ser humano no ambiente social. As duas perspectivas podem ser

\footnotetext{
${ }^{18}$ MILL, Stuart. Sobre a liberdade. Tradução e organização: Ari R. Tank. São Paulo: Hedra, 2010, p. 49.

${ }^{19}$ MILL, Stuart. Sobre a liberdade. Tradução e organização: Ari R. Tank. São Paulo: Hedra, 2010, p. 49.

${ }^{20}$ MILL, Stuart. Sobre a liberdade. Tradução e organização: Ari R. Tank. São Paulo: Hedra, 2010, p. 58.
} 
compreendidas dentro de um contexto denominado liberalismo clássico no qual a liberdade torna-se o valor fundamental do indivíduo.

\section{RAWLS, A LIBERDADE E O PLURALISMO}

O conceito de liberdade se relaciona com o conceito de Direito, especialmente com conceito de direito fundamental capaz de preservar e resguardar o indivíduo frente à ingerência do poder estatal dos demais concidadãos. A interseção entre liberdade e Direito também se conecta com o conceito de Poder Político uma vez que se trata de regulamentação de comportamentos dos indivíduos dentro da sociedade. Logo, pela via do Poder Político estabelecem-se normas (qualificadas como jurídicas) que visam regular os espaços e limites da ação do indivíduo no ambiente social. Para a compreensão de uma perspectiva de Justiça com pretensões de normatividade, é necessário entender quais as razões que levam uma sociedade a se constituir e a se organizar enquanto estrutura de cooperação social entre indivíduos livres e iguais. ${ }^{21}$ Portanto, o conceito de liberdade corresponde à necessária articulação entre a autonomia moral do indivíduo (compreendida como a possibilidade de ação nas relações entre particulares) e autonomia política (considerada como aquela exercida publicamente na formação dos sentidos normativos nos espaços institucionalizados) capaz delimitar os espaços de ação individual dentro do ambiente social diverso e plural através de normas de comportamento.

Desafiando o intuicionismo, o perfeccionismo e, especialmente, o utilitarismo, Rawls propõe uma filosofia normativa (deontológica) fixando como pressuposto de seu pensamento alguns elementos do liberalismo clássico. O ponto de partida de Rawls, como já apresentado na introdução, é o primeiro princípio de justiça denominado como princípio liberal. Segundo Rawls, a previsão e a garantia de um amplo sistema de liberdades conferidas aos cidadãos de uma dada sociedade devem ser capazes de fundamentar o pluralismo (razoável) preservando das doutrinas abrangentes razoáveis. Rawls adota como pressuposto o fato do pluralismo razoável que “(...) consiste em profundas e irreconciliáveis diferenças nas concepções religiosas e filosóficas,

${ }^{21}$ FONSECA, Maria Fernanda Soares; FERREIRA, Maria da Luz Alves. AS TEORIAS DA JUSTIÇA: UM CONTRAPONTO ENTRE AS CONCEPÇÕES DE JOHN RAWLS E ROBERT NOZICK. Revista Eletrônica do Curso de Direito da UFSM, Santa Maria, RS, v. 11, n. 2, p. 601-617, ago. 2016. ISSN 1981-3694. Disponível em: https://periodicos.ufsm.br/revistadireito/article/view/21015. Acesso em: 09 maio 2019 . doi: http://dx.doi.org/10.5902/1981369421015. 
razoáveis e abrangentes, que os cidadãos têm do mundo, e na idéia que eles têm dos valores morais e estéticos a serem alcançados na vida humana". ${ }^{22}$

Para Rawls, sociedades democráticas não se mantém estáveis porque os indivíduos compartilham os mesmos valores ou por uma mesma 'doutrina abrangente'. Partindo-se da autonomia individual de cada cidadão, segundo a qual cada indivíduo possui a capacidade racional de escolher os fins para sua própria vida, a convergência de todos os fins individuais não é possível dentro de um ambiente democrático. Assim, as sociedades democráticas devem buscar a conciliação das 'doutrinas abrangentes razoáveis' num mesmo espaço e tempo. Rawls propõe a ideia de 'doutrina abrangente' como aquela que representa perspectivas divergentes e inconciliáveis, mas, ainda sim, toleráveis dentro de uma sociedade plural. A aceitação das doutrinas abrangentes razoáveis pelo liberalismo político se relaciona com o conceito de tolerância das formas diversas de pensamento.

Para Rawls, a sociedade é um empreendimento cooperativo que, para ser considerado um sistema equitativo, deve apresentar (a) uma regulação por normas e procedimentos publicamente reconhecidos pelos cidadãos, (b) o reconhecimento dos termos equitativos que possam ser aceitos pelos cidadãos e (c) uma noção de vantagem racional ou do bem de cada cidadão. ${ }^{23}$

A aceitação do argumento de que os cidadãos são indivíduos livres e iguais leva a uma concepção de sociedade democrática cujo pressuposto é a autonomia dos indivíduos no tocante a sua capacidade de tomar decisões. A autonomia individual é denominada por Rawls de faculdade moral dos cidadãos. ${ }^{24}$ Os indivíduos possuem duas faculdades morais: (a) faculdade racional, relacionada à capacidade de cada indivíduo possuir uma concepção de bem e (b) faculdade razoável, relacionada à capacidade de cada indivíduo possuir um senso de justiça. Nos limites do presente ensaio, enfatiza-se a capacidade racional uma vez que se busca um fundamento teórico capaz de dar conteúdo ao conceito de liberdade e, ao mesmo tempo, capaz de ser racionalmente sustentado no espaço público.

A liberdade, o fato do pluralismo e a tolerância em Rawls buscam afastar as concepções metafísicas de Justiça. Portanto, o tema da Justiça é recolocado no debate público a partir da capacidade dos cidadãos de dialogar sobre as bases normativas da convivência comum. Esse

${ }^{22}$ RAWLS, John. Justiça como equidade. Uma reformulação. Tradução Cláudia Berliner; revisão técnica Álvaro de Vita. São Paulo: Martins Fontes, 2003, p. 04.

${ }^{23}$ RAWLS, John. Liberalismo Político. Tradução de Álvaro de Vita. São Paulo: Editora WMF Martins Fontes, 2011, p. 18.

${ }^{24}$ RAWLS, John. Liberalismo Político. Tradução de Álvaro de Vita. São Paulo: Editora WMF Martins Fontes, 2011, p. 56-107. 
diálogo deve articular os conceitos de liberdade e tolerância, preservando e até mesmo fomentando a diversidade e o pluralismo. O sistema de liberdades individuais previsto no primeiro princípio de justiça de Rawls cumpre um papel fundamental no estabelecimento do conceito político de justiça.

O reconhecimento da capacidade moral dos cidadãos livres e iguais coloca o indivíduo como protagonista da própria decisão sobre os termos equitativos de cooperação gerando duas consequências: (a) insere o indivíduo dentro de uma relação intersubjetiva instaurando a dimensão ética à medida que o cidadão deve estar comprometido tanto com sua própria fala [com seus próprios argumentos] quanto com a fala do outro [reciprocidade]; e (b) torna o indivíduo publicamente responsável pelo reconhecimento e legitimidade da normatividade social produzida a partir dos procedimentos discursivos de deliberação pública e das práticas sociais para a construção das normas jurídicas.

A possibilidade de se construir um sistema normativo exige um regime político democrático ao mesmo tempo em que pressupõe que a razão seja exercida publicamente. Como exercer o Poder Político de forma justificável perante os cidadãos? Adotando-se um modelo de Estado Constitucional Democrático, os sentidos normativos devem ser construídos discursivamente por meio de uma argumentação pública cujo objetivo é uma justificação intersubjetiva [racional] das normas de convivência social.

Nesse sentido, a condição política humana deve ser compreendida no estar com/contra/a favor dos concidadãos, isto é, o indivíduo está sempre diante da alteridade no exercício de sua autonomia. A liberdade individual, reivindicada pela faculdade racional dos indivíduos, torna-se o fundamento radical das possibilidades de estabelecimento de convivência das diferentes perspectivas individuais dentro do ambiente social. Portanto, a igual capacidade moral dos cidadãos e o exercício da razão individual nos espaços públicos capazes de fabricar sentidos normativos fundamentam aquilo que Rawls denomina de uma Concepção Política de Justiça. ${ }^{25}$

Para ser protagonista no ambiente social o cidadão deve ter, prioritariamente, acesso a um sistema plenamente adequado de liberdades fundamentais compreendidas como liberdade de pensamento, liberdade de expressão, liberdade de manifestação e liberdade de participação dos procedimentos de deliberação. O primeiro princípio de justiça exige, ainda, que esse sistema de liberdades fundamentais esteja disponível de forma igualitária, ou seja, cada cidadão deve ter acesso ao mesmo rol de liberdades fundamentais. É justamente por ser livre, isto é, por

${ }^{25}$ CAMILLOTO, Bruno. Direito, Democracia e Razão Pública. Belo Horizonte: Editora D’ Plácido, 2016. 
possuir uma autonomia moral individual irredutível, que cada cidadão deve ser tratado igualitariamente do ponto de vista normativo.

A inexorável tensão entre a autonomia individual e a alteridade social reivindica o estabelecimento de espaços dialógicos e discursivos que permitam a construção do conteúdo do conceito de liberdade. 0 critério de reciprocidade pressupõe que os cidadãos, no uso de suas faculdades do racional e do razoável, estabeleçam suas relações intersubjetivas como pessoas autônomas e reconhecedoras da autonomia individual dos seus concidadãos. A reciprocidade da liberdade individual pode fundar as bases para a tolerância em uma sociedade caracterizada pelo pluralismo.

A compreensão do conceito de liberdade pode ser pensada em dois momentos: (a) como compreensão da possibilidade de ação fundada na autonomia moral individual uma vez que os indivíduos são sujeitos racionais capazes, portanto, de decidir sobre os próprios projetos de vida. Esse argumento é a reivindicação que o indivíduo faz para si da sua liberdade. (b) ao reivindicar para si a liberdade (autonomia moral), o indivíduo deve pressupor que seus concidadãos também possuem a mesma capacidade racional para fazer essa reivindicação, logo, cada indivíduo deve levar em igual consideração as reivindicações dos demais dentro de um ambiente social. Nesse contexto de relação intersubjetiva, a defesa da liberdade individual constitui-se num argumento moral de segunda ordem capaz de fundar uma sociedade plural na qual a preservação da diversidade é condição sine qua non.

Esse conceito de liberdade é capaz de propiciar que os cidadãos (indivíduos livres e racionais) sejam responsáveis pelo estabelecimento dos próprios termos equitativos de convivência que gerarão uma Concepção Política de Justiça. Considerando-se, portanto, um regime democrático e constitucional, a Concepção Política de Justiça explicita o conteúdo da razão pública e tem por consequências (a) o estabelecimento de determinados direitos, liberdades e oportunidades fundamentais, (b) a atribuição de prioridade especial aos direitos, liberdades e oportunidades fundamentais e (d) o estabelecimento de medidas que assegurem a todos cidadãos mecanismos de exercício desses direitos, liberdades e oportunidades fundamentais. ${ }^{26}$

${ }^{26}$ RAWLS, John. Liberalismo Político. Tradução de Álvaro de Vita. São Paulo: Editora WMF Martins Fontes, 2011, p. 263. 


\section{CONCLUSÃO}

A questão apresentada no título deste ensaio diz respeito às possibilidades de compreensão do conceito de liberdade como fundamento para uma sociedade plural. Para tanto, recuperou-se os elementos centrais do liberalismo clássico de Locke e Mill cujos objetivos foram: (a) defender uma concepção de liberdade a partir do Estado de Direito e (b) defender uma concepção de liberdade individual capaz de fornecer substrato teórico e prático para compreensão do indivíduo como um ser racional, isto é, dotado de autonomia moral.

Em Locke tem-se que o conceito de liberdade individual interdita o poder público de ditar regras sobre os planos de vida dos cidadãos, isto é, Locke fornece as bases teóricas para se pensar na construção de um sistema de garantias individuais contra a interferência do poder do Estado na esfera do indivíduo. Locke traz, ainda, o elemento do consentimento para legitimar o exercício do poder estatal.

Em Mill, o conceito de liberdade fornece elementos necessários ao estabelecimento de uma esfera de ação individual que deva ser a mais ampla possível limitada, apenas, em caso de causação de dano a outrem. Assim, os indivíduos devem, necessariamente, tolerar as diferentes perspectivas e projetos de vida no interior da sociedade em nome da diversidade e do pluralismo sob pena de violação da liberdade individual.

Rawls atualiza os fundamentos do liberalismo clássico em dois sentidos: (a) inicialmente propõe o primeiro princípio de justiça que consagra um amplo sistema de liberdades fundamentais. Esse princípio é lexical na proposta de Rawls sendo, portanto, condição necessária para um regime normativo de convivência plural e democrático e (b) atribui prioridade às liberdades fundamentais, isto é, propõe que aquele sistema de liberdades que configuram o primeiro princípio de justiça seriam os escolhidos pelos indivíduos racionais e razoáveis prioritariamente a qualquer outro sistema normativo de convivência.

A questão prática que se colocou à reflexão é: qual conceito normativo é capaz de abrigar, dentro do seu conteúdo, concepções individuais de bem antagônicas? Por exemplo, aquelas concepções de um indivíduo que crê em algum dogma de fé (religiosidade) e outro que não possui crença religiosa. A convivência social entre o "crente" e o ateu só é possível se o conceito de liberdade for pensado em sua radicalidade como o lugar privilegiado de articulação entre essas diferenças individuais inconciliáveis. 
Defende-se que, pensado radicalmente como possibilidade de desenvolvimento da autonomia moral dos indivíduos, o conceito de liberdade é capaz de fundamentar uma sociedade plural. Essa fundamentação deve ser compreendida pelo aspecto normativo, ou seja, a liberdade individual deve ser um conceito capaz de (a) organizar os comportamentos dos indivíduos no âmbito de uma dada sociedade compatibilizando às diferentes concepções de bem e (b) limitar a interferência do poder público na esfera da autonomia moral individual. Sendo assim, a radicalidade do conceito de liberdade consiste na possibilidade de ele conseguir justificar racionalmente uma sociedade plural preservando a diversidade individual.

Ao preservar na mesma estrutura social concepções antagônicas de bem (como, no exemplo, o "crente" e o ateu), sem sobreposição de uma perspectiva sobre a outra, a liberdade política institucionalizada como direito de liberdade atribuído ao indivíduo é o conceito capaz de produzir um ambiente social diverso e plural na medida em que preserva as diferentes concepções individuais. Logo, o conceito de liberdade torna-se condição necessária para pensar (e fomentar) as sociedades políticas que pretendem ser plurais.

Frise-se que a partir da modernidade o conceito de liberdade está relacionado com o âmbito privado de tomada de decisão na qual a independência individual se torna a primeira das necessidades do ser humano. A liberdade é o conceito que permite o desenvolvimento de todos os aspectos da vida privada. Logo, a sociedade política moderna deve compor a liberdade dos indivíduos de forma a permitir aos indivíduos o exercício pacífico das esferas de atuação e deliberação privada. Nesse contexto, a liberdade individual pode ser concebida como a liberdade moderna nos contornos do Estado de Direito. A liberdade política, por sua vez, tornase a garantia da liberdade individual na medida em que a preservação desta depende de um arcabouço normativo capaz de garantir aos indivíduos o exercício de sua autonomia moral.

$\mathrm{Na}$ perspectiva do liberalismo, o conceito de indivíduo é o centro de imputação do conceito de liberdade compreendida como autonomia moral dos indivíduos. 0 liberalismo é um discurso racional em defesa da liberdade no campo político exigindo proteção das liberdades individuais na forma de direitos. A liberdade é a condição necessária do pluralismo. Por fim, a liberdade é o fundamento radical de uma sociedade plural. 


\section{REFERÊNCIAS}

CAMILLOTO, Bruno. Direito, Democracia e Razão Pública. Belo Horizonte: Editora D’ Plácido, 2016.

DALAQUA, Gustavo Hessman. A defesa miliana da liberdade de expressão. Fundamento Revista de Pesquisa em Filosofia, v. 1, n. 3, maio-ago. 2011. Disponível em:

http://www.revistafundamento.ufop.br/index.php/fundamento/article/view/40/31. Acesso em: 15 jan. 2017.

DANNER, Leno Francisco. A reformulação do liberalismo clássico por John Rawls. Fundamento Revista de Pesquisa em Filosofia, v. 1 n. 3, maio - ago. 2011. Disponível em:

http://www. revistafundamento.ufop.br/index.php/fundamento/article/view/41/32. Acesso em: 15 jan. 2017.

FONSECA, Maria Fernanda Soares; FERREIRA, Maria da Luz Alves. AS TEORIAS DA JUSTIÇA: UM CONTRAPONTO ENTRE AS CONCEPÇÕES DE JOHN RAWLS E ROBERT NOZICK. Revista Eletrônica do Curso de Direito da UFSM, Santa Maria, RS, v. 11, n. 2, p. 601-617, ago. 2016. ISSN 19813694. Disponível em: https://periodicos.ufsm.br/revistadireito/article/view/21015. Acesso em: 09 maio 2019. doi: http://dx.doi.org/10.5902/1981369421015.

LOCKE, John. A letter concerning toleration. Translated by Willian Popple, 1689. Disponível em: http://www.dominiopublico.gov.br/download/texto/mc000173.pdf. Acesso em: 26 jan. 2017.

LOCKE, John. Segundo tratado sobre o governo civil. Tradução Marsely de Marco Dantas; Apresentação de notas Daniel Moreira Miranda. São Paulo: EDIPRO, 2014.

MILL, Stuart. Sobre a liberdade. Tradução e organização: Ari R. Tank. São Paulo: Hedra, 2010.

RAWLS, John. Justiça como equidade. Uma reformulação. Tradução Cláudia Berliner; revisão técnica Álvaro de Vita. São Paulo: Martins Fontes, 2003.

RAWLS, John. Uma teoria da justiça. Tradução Jussara Simões; revisão técnica Álvaro de Vita. $3^{\mathrm{a}}$ ed. São Paulo: Martins Fontes, 2008.

RAWLS, John. Liberalismo Político. Tradução de Álvaro de Vita. São Paulo: Editora WMF Martins Fontes, 2011. 


\section{COMO FAZER REFERÊNCIA AO ARTIGO (ABNT):}

CAMILLOTO, Bruno. Liberdade: a condição de possibilidade do pluralismo a partir do pensamento de Rawls. Revista Eletrônica do Curso de Direito da UFSM, Santa Maria, RS, v. 14, n. 3, e31429, set./dez. 2019. ISSN 19813694. DOI: http://dx.doi.org/10.5902/1981369431429. Disponível em:

https://periodicos.ufsm.br/revistadireito/article/view/31429 Acesso em: dia mês. ano.

Direitos autorais 2019 Revista Eletrônica do Curso de Direito da UFSM

Editores responsáveis: Rafael Santos de Oliveira e Angela Araujo da Silveira Espindola

\section{BY no nD}

Este obra está licenciado com uma Licença Creative Commons Atribuição-NãoComercial-SemDerivações 4.0 Internacional.

\section{SOBRE O AUTOR}

\section{BRuno Camilloto}

Professor de Direito da Universidade Federal de Ouro Preto (UFOP) na graduação e no Programa de Pós-Graduação (Novos Direitos, Novos Sujeitos). Doutor em Direito pela Pontifícia Universidade Católica de Minas Gerais (PUC-MG). Mestre em Direito pela Universidade Federal de Minas Gerais (UFMG). Especialista em Gestão Pública e Bacharel em Direito pela UFOP 